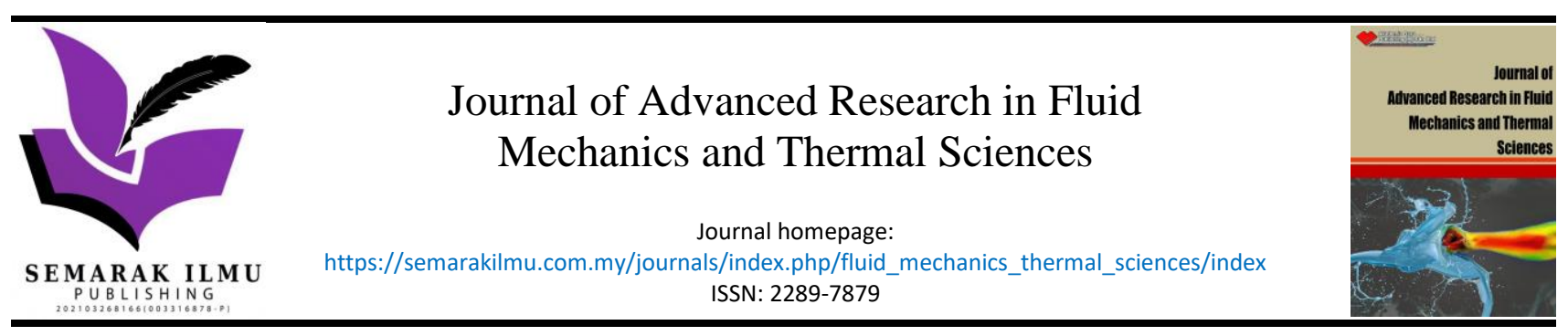

\title{
MHD Heat and Mass Transfer Steady Flow of a Convective Fluid Through a Porous Plate in The Presence of Diffusion Thermo and Aligned Magnetic
} Field

\author{
Obulesu Mopuri ${ }^{1}$, Raghunath Kodi ${ }^{2}$, Charankumar Ganteda ${ }^{3}$, Ramu Srikakulapu ${ }^{4}$, Giulio Lorenzini ${ }^{1,5,{ }^{*}}$ \\ Department of Mathematics, Siddharth Institute of Engineering and Technology, Puttur, Andhra Pradesh, India \\ Department of Mathematics, Bheema Institute of Technology \& Science, Adoni-518301, Andhra Pradesh, India \\ 3 Department of Mathematics, Koneru Lakshmaiah Education Foundation (KL deemed to be University), Greenfields, Vaddeswaram, Guntur- \\ 522502, India \\ 4 Department of EEE,Vignan's Institute of Information Technology(A),Visakhapatnam-530049, India \\ University of Parma, Department of Engineering and Architecture, Parco Area delle Scienze 181/A, Parma 43124, Italy
}

\section{ARTICLE INFO}

\section{Article history:}

Received 28 July 2021

Received in revised form 1 October 2021

Accepted 9 October 2021

Available online 19 November 2021

\section{ABSTRACT}

Keywords:

Diffusion thermo; Radiation absorption; inclined angle; aligned magnetic field; chemical reaction

\begin{abstract}
In the presence of a diffusion thermal and coupled magnet field effect, this manuscript seeks continuous free convective motion by a viscous, incompressible fluid that conducts electrically past a sloping platform via a porous medium. The free flow speed may be compatible with the exponentially tiny disrupting law. Two-term harmonic and nonharmonic functions solve dimensional-less control equations analytically. Detailed graphs are used to determine the budgets for tempo, temperature, and concentration for various limit calculations. Also, the numbers of Nusselt and Sherwood are given and evaluated with the graphs. Its sketches illustrate that the velocity profiles get reduced by the increase of aligned magnetic field parameter $(\alpha)$ and inclined angle parameter ( $\xi)$. Temperature profile is accelerated by rising heat absorption, Dufour number and concentration distribution is decelerated by enhancing the chemical reaction and Schmidt number. Heat and mass transfer frequently occurs in chemically processed industries, distribution of temperature and moisture over agricultural fields, dispersion of fog and environment pollution and polymer production. Free convection flow of coupled heat and mass transfer occurs due to the temperature and concentration differences in the fluid as a result of driving forces. For example, in atmospheric flows, thermal convection resulting from heating of the earth by sunlight is affected differences in water vapour concentration.
\end{abstract}

\section{Introduction}

The diffusion is the net migration of something from a region of higher concentration to a part of lower concentration (e.g., particle, ions, and molecules). A concentration curve regulates distribution. In several application areas, the principle of diffusion is commonly applicable, including physics (particular diffusion), chemistry, genetics, economics, and finance. Moreover, both of these

\footnotetext{
* Corresponding author.

E-mail address: giulio.lorenzini@unipr.it
}

https://doi.org/10.37934/arfmts.89.1.6276 
are acquainted with the central notion of distribution: an entity (e.g., particle, concept, etc.), which is diffused expands from a point or place at which the entity is more focused. A gradient is a difference in the values of a number, i.e., concentration, strain, or temperature, typically distance while changing in another variable. Position shifts are called a concentration gradient, a position shift is called a pressure gradient, and a distance change is called a temperature gradient.

In an environment where heat is produced and resultantly a mixed MHD convection flow in case of Jeffrey fluid is obtained this flow is observed through a radiating, inclined permeable moving layer is possessed by Raju et al., [1]. Vedavathi et al., [2] have expressed Casson magneto hydro mechanics fluid flow chemical reactions, radiation, and Dufour results in a vertical plate of heat source/sink. The dimensional magnetic field and the resultant diffusion effect on the unstable convective MHD flow passing through a sloped has been studied by Ramaiah and Prasad [3]. Normal convection over a platform was first experimentally studied by Rich [4]. Chen et al., [5] provide a computational approach on an inclined object with temperature variant surface giving rise to natural convection. $\mathrm{Yu}$ and Lin [6] explained the phenomenon of heat transmission from an object randomly inclined angle. Muthucumaraswamy [7] Explains thermal and hydromagnetic radiations impact on the unstable flow in an environment where the isothermal plate is inclined in an oscillating position. Ramaprasad et al., [8] have analysed the free convective flow via a moveable leaning region of the electrically conductive fluid with substantial viscosity via in environment of the magnetic field. The unsteady hydrodynamic chemical reactive viscoelastic fluid flow was tested by Kumaresan and Kumar [9] have discovered by via a plate subjected to heat 'borne radiation with uniform temperature. Very recently Balamurugan and Murthy [10] have examined a vertically inclined object having pores and noted a prevalent thermo dynamic reaction giving rise to viscous. Chemical reaction engineering (reaction engineering or reactor engineering) is a specialty in chemical engineering or industrial chemistry dealing with chemical reactors. Frequently the term relates specifically to catalytic reaction systems where either a homogeneous or heterogeneous catalyst is present in the reactor. For example, in reactive separations, vessels, retorts, certain fuel cells and photo catalytic surfaces. The issue of solvent effects on reaction kinetics is also considered as an integral part. Reactor design uses information, knowledge and experience from a variety of areas - thermodynamics, chemical kinetics, fluid mechanics, heat and mass transfer and economics. Chemical reaction engineering is the synthesis of all these factors with the aim of properly designing a chemical reactor. Nandkeolyar et al., [11] studied the effect of chemical reaction and heat absorption on MHD nano liquid flow past a stretching sheet in the presence of a transverse magnetic field. Mohapatra et al., [12] investigated the effect of chemical reaction on MHD micropolar fluid flow on a vertical surface through porous media with heat source. Srinivas Reddy [13] analyzed the Impact of chemical reaction on MHD free convection heat and mass transfer from vertical surfaces in porous media considering thermal diffusion and diffusion thermo effects. Sheri and Shamshuddin [14] studied diffusion-thermo and chemical reaction effects on an unsteady MHD free convection flow in a micropolar fluid diffusion-thermo and chemical reaction effects on an unsteady MHD free convection flow in a micropolar fluid. Malik and Khalil-urRehman [15] studied effects of second order chemical reaction on MHD free convection dissipative fluid flow past an inclined porous surface by way of heat generation. Salbi et al., [21] the effect of coating material composition on the encapsulation of physical and chemical properties of fig powder was investigated. As coating material maltodextrin and acacia gum at different ratios were chosen (100\% and 75\%:25\%). The core to coating ratio was 1:1. Khan et al., [22] The present study analyses the magnetohydrodynamic (MHD) flow of a double stratified micropolar fluid across a vertical stretching/shrinking sheet in the presence of suction, chemical reaction, and heat source effects. The governing equations in the form of partial differential equations are transitioned into coupled nonlinear ordinary differential equations by means of similarity transformation. Phu et al., [23] a 
nanofluid-based solar collector duct equipped with baffles is examined numerically. Baffles are located on the back plate to guide nanofluid flow toward absorber plate for heat transfer enhancement purposes. Cu-water nanofluid with fixed flow rate and concentration in the baffled duct are investigated for thermohydraulic mechanisms. Baffles with different inclination angles, heights and pitches are considered in this study. Mahat et al., [24] researched on the nanofluid becomes trending amongst researchers especially in the industrial and engineering field due to its important and extensive applications. Therefore, the present study aims to investigate numerically the impact of viscous dissipation conducted by sodium carboxymethyl cellulose (CMC-water) nanofluid containing copper nanoparticles at room temperature with convective boundary conditions (CBC) [25]. In recent years, there has been an increasing interest in heat transfer enhancement using nanofluids in channels due to current devices become smaller and more compact and are expected to perform better. Thus, we attempt to introduce hybrid nanofluids flow in a straight pipe using Ansys Fluent software. The simulation was prepared with certain specific parameters such as the hydraulic diameter is set at $10 \mathrm{~mm}$, the flow is a continuum, the Reynold number in the range of 5000 to 30000 , k-cturbulent model used in this simulation, the inlet temperature $297 \mathrm{~K}$, and the uniform temperature along the pipe at $313 \mathrm{~K}$. This study was carried out on $\mathrm{Al}_{2} \mathrm{O}_{3}+\mathrm{Cu} / \mathrm{water}$ hybrid nanofluids to analyse the thermal improvement and friction factor of nanofluids occur in a straight pipe.

\section{Derivation of the Problem}

Render turbulent bi-dimensional flux of laminar fluid during chemical and fragrant reactions, incompressible, electrically conductive, and thermally absorbing fluid via an object that is inclined and inserted in a medium having portes. The object is expected to flow in the $\mathrm{x}$-dimension around the semi-infinite tilted scale and the $y$-axis. A Same force magnetic field $B_{0}$ is reached at an angle $\alpha$ to the flow path. The free-stream pace expressed the exponentially rising rule on minor disturbances.

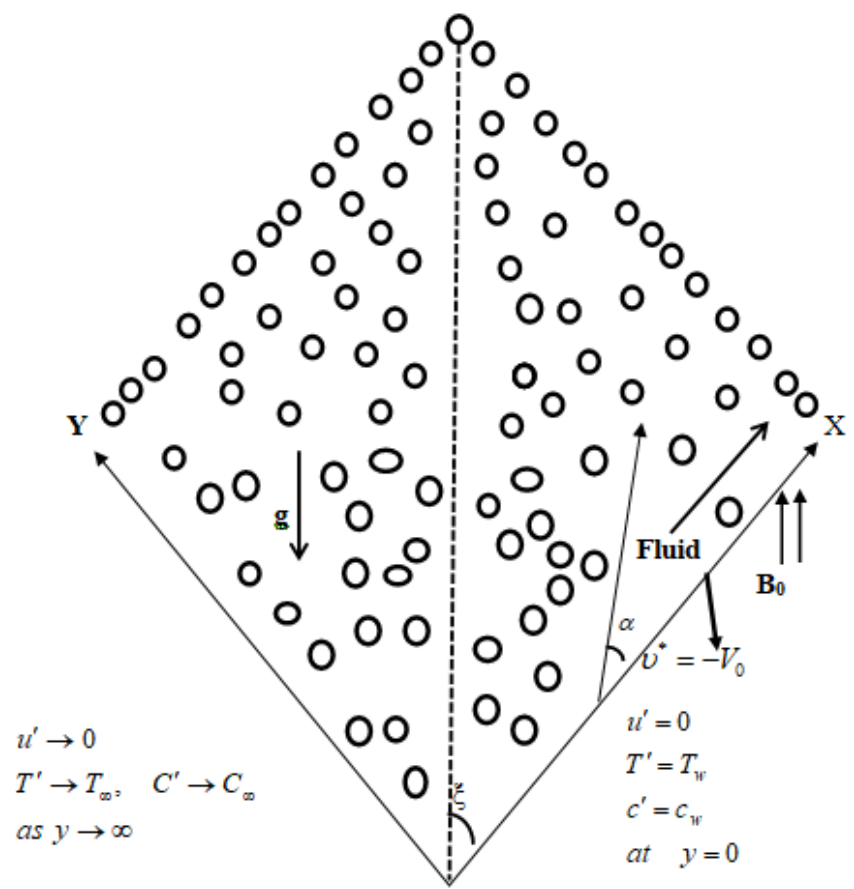

Fig. 1. Physical model of the problem 
Moreover, the temperature and concentration on the wall and the suction intensity are believed to differ exponentially with time. This analysis's leading equations are focused on the mass, linear dynamic, energy, and concentration equilibrium.

$$
\begin{aligned}
& \frac{\partial v^{\prime}}{\partial y^{\prime}}=0 \\
& v^{\prime} \frac{\partial u^{\prime}}{\partial y^{\prime}}=\vartheta \frac{\partial^{2} u^{\prime}}{\partial y^{\prime 2}}+g \beta\left(T^{\prime}-T_{\infty}^{\prime}\right) \cos \xi+g \beta^{\prime}\left(C^{\prime}-C_{\infty}^{\prime}\right) \cos \xi-\sin ^{2} \alpha \frac{\sigma B_{0}^{2}}{\rho} u^{\prime}-\vartheta \frac{u^{\prime}}{K_{p}} \\
& v^{\prime} \frac{\partial T^{\prime}}{\partial y^{\prime}}=\frac{K}{\rho C_{p}} \frac{\partial^{2} T^{\prime}}{\partial y^{\prime 2}}+\frac{\vartheta}{C_{p}}\left(\frac{\partial u^{\prime}}{\partial y^{\prime}}\right)^{2}-\frac{1}{\rho C_{p}} \frac{\partial q_{r}^{\prime}}{\partial y^{\prime}}-\frac{Q_{1}}{\rho C_{p}}\left(T^{\prime}-T_{\infty}^{\prime}\right) \\
& v^{\prime} \frac{\partial C^{\prime}}{\partial y^{\prime}}=D \frac{R_{1}}{\rho C_{p}}\left(C^{\prime}-C_{\infty}^{\prime}\right)+\frac{D K_{T}}{\partial y^{\prime 2}}-K_{C}\left(C^{\prime}-C_{\infty}^{\prime}\right)
\end{aligned}
$$

The respective limits are given as follows

$$
\begin{array}{lll}
u^{\prime}=0 & T^{\prime}=T_{w}, & C^{\prime}=C_{w} \text { at } y=0 \\
u^{\prime} \rightarrow 0 & T^{\prime} \rightarrow T_{\infty}, & C^{\prime} \rightarrow C_{\infty} \text { as } y \rightarrow \infty
\end{array}
$$

Eq. (1) gives that

$\mathrm{V}^{*}=$ Constant $=-\mathrm{V}_{0}$

The fluid does not consume its radiation concentrations at the optically dense maximum but absorbs radiation from the boundaries. Cogley et al., [20] found that a non-gray gas close to the balance is optically thick, as seen below.

$$
\frac{\partial q_{r}}{\partial y^{\prime}}=4\left(T^{\prime}-T_{\infty}^{\prime}\right) \int_{0}^{\infty} K_{\lambda w} \frac{d e_{b \lambda}}{d T^{\prime}} d \lambda=4 I_{1}\left(T^{\prime}-T_{\infty}^{\prime}\right)
$$

Implemented the dimensionless quantities,

$$
\begin{aligned}
& u=\frac{u^{\prime}}{v_{0}}, y=\frac{v_{0} y^{\prime}}{\vartheta}, \operatorname{Pr}=\frac{\vartheta \rho C_{p}}{K}, \theta=\frac{T^{\prime}-T_{\infty}^{\prime}}{T_{w}-T_{\infty}^{\prime}}, \phi=\frac{C^{\prime}-C_{\infty}^{\prime}}{C_{w}-C_{\infty}^{\prime}} S c=\frac{\vartheta}{D}, M=\frac{\sigma B_{0}^{2} \vartheta}{\rho v_{0}^{2}}, \\
& G r=\frac{\left(T_{w}-T_{\infty}^{\prime}\right) \vartheta g \beta}{v_{0}^{3}}, G m=\frac{\left(C_{w}-C_{\infty}^{\prime}\right) \vartheta g \beta^{\prime}}{v_{0}^{3}} E=\frac{v_{0}^{2}}{C_{P}\left(T_{w}-T_{\infty}^{*}\right)}, K=\frac{v_{0}^{2} K_{P}}{\vartheta^{2}} \\
& K_{0}=\frac{\vartheta K_{C}}{v_{0}^{2}}, F=\frac{4 I_{1} \vartheta^{2}}{K v_{0}^{2}}, Q=\frac{Q_{1} v^{2}}{K v_{0}^{2}}, R=\frac{R_{1} v^{2}\left(C_{w}-C_{\infty}^{\prime}\right)}{K v_{0}^{2}\left(T_{w}-T_{\infty}^{\prime}\right)}, \quad D u=\frac{D K_{T}}{v C_{s} C_{p}} \frac{\left(C_{w}-C_{\infty}^{\prime}\right)}{\left(T_{w}-T_{\infty}^{\prime}\right)}
\end{aligned}
$$


Where $\mathrm{M}$ is a magnetic specification, $\mathrm{E}$ is the Eckert specification, $\mathrm{K}$ is a specification for permeability, $\mathrm{K}_{0}$ is the parameter for the chemical reaction, $\mathrm{F}$ is the radiation specification, $\mathrm{Q}$ is the heat source specification, and Du is the Dufour specification. The non-dimensional shape of the controls (2)-(4) reduces.

$u^{\prime \prime}+u^{\prime}=-\mathrm{Gr} \cos \xi \theta-\mathrm{Gm} \cos \xi \phi+\mathrm{M}_{1} \mathrm{u}$

$\theta^{\prime \prime}+\operatorname{Pr} \theta^{\prime}-(\mathrm{F}+\mathrm{Q}) \theta=-\operatorname{PrE} u^{1^{2}}-R \phi-D u \phi^{\prime \prime}$

$\phi^{\prime \prime}+\operatorname{Sc} \phi^{\prime}-\mathrm{ScK}_{0} \phi=0$

Where $M_{1}=\left(M \sin ^{2} \alpha+\frac{1}{K}\right)$

The corresponding limits are defined by

$$
\begin{array}{llll}
u=0, & \theta_{1}=1, & \phi_{1}=1 & \text { at } y=0 \\
u \rightarrow 0, & \theta \rightarrow 0, & \phi \rightarrow 0 & \text { as } y \rightarrow \infty
\end{array}
$$

\section{Solution of the Problem}

To overcome the coupled nonlinear equation method, Eq. (9) to Eq. (11) The following fundamental perturbation is used for boundary conditions (12). The controlling equivalent parameters (9) to (11) are extended to include Eckert number $E(<<1)$.

$$
F(y, t)=F_{0}(y)+E F_{1}(y)+O\left(E^{2}\right)
$$

Where $u, \theta, \phi$ are the function in terms of velocity, temperature and concentration.

The following equations were achieved by substituting Eq. (13) to Eq. (9)-(11) and equating coefficients to terms of the same powers of $E$, and by disregarding terms of a higher order.

\subsection{Zero Order Terms}

$u_{0}^{\prime \prime}+u_{0}^{\prime}=-\mathrm{Gr} \cos \xi \theta_{0}-\mathrm{Gm} \cos \xi \phi_{0}+\mathrm{M}_{1} \mathrm{u}_{0}$

$\theta_{0}^{\prime \prime}+\operatorname{Pr} \theta_{0}^{\prime}-(\mathrm{F}+\mathrm{Q}) \theta_{0}=-\mathrm{R} \phi_{0}-D u \phi_{0}^{\prime \prime}$

$\phi_{0}^{\prime \prime}+\operatorname{Sc} \phi_{0}^{\prime}-\mathrm{ScK}_{0} \phi_{0}=0$

\subsection{First Order Terms}

$u_{1}^{\prime \prime}+u_{1}^{\prime}=-\mathrm{Gr} \cos \xi \theta_{1}-\mathrm{Gm} \cos \xi \phi_{1}+\mathrm{M}_{1} \mathrm{u}_{1}$ 


$$
\begin{aligned}
& \theta_{1}^{\prime \prime}+\operatorname{Pr} \theta_{1}^{\prime}-(\mathrm{F}+\mathrm{Q}) \theta_{1}=-\operatorname{Pru}_{0}^{1^{2}}-R \phi_{1}-D u \phi_{1}^{\prime \prime} \\
& \phi_{1}^{\prime \prime}+S c \phi_{1}^{\prime}-S c K_{0} \phi_{1}=0
\end{aligned}
$$

The derived resultant conditions are

$$
\begin{array}{llll}
u_{0}=0, \quad u_{1}=0, & \theta_{0}=1, \quad \theta_{1}=0, & \phi_{0}=1, \phi_{1}=0 & \text { at } y=0 \\
u_{0} \rightarrow 0, u_{1} \rightarrow 0, & \theta_{0} \rightarrow 0, \theta_{1} \rightarrow 0, & \phi_{0} \rightarrow 0, \phi_{1} \rightarrow 0 & \text { as } y \rightarrow \infty
\end{array}
$$

The following solutions are obtained under boundary conditions

$$
\begin{aligned}
\phi_{0}= & e^{-m_{1} y} \\
\theta_{0}= & l_{1} e^{-m_{1} y}+\left(1-l_{1}\right) e^{-m_{2} y} \\
u_{0}= & l_{3} e^{-m_{1} y}+l_{4} e^{-m_{2} y}+\left(-l_{2}-l_{3}\right) e^{-m_{3} y} \\
\theta_{1}= & l_{6} e^{-2 m_{1} y}+l_{5} e^{-2 m_{2} y}+l_{4} e^{-2 m_{3} y}+l_{7} e^{-m_{4} y}+l_{8} e^{-m_{5} y} \\
& +l_{9} e^{-m_{6} y}+l_{10} e^{-m_{2} y} \\
& \\
u_{1}= & l_{13} e^{-2 m_{1} y}+l_{12} e^{-2 m_{2} y}+l_{11} e^{-2 m_{3} y}+l_{14} e^{-m_{4} y}+l_{15} e^{-m_{5} y} \\
& +l_{16} e^{-m_{6} y}+l_{17} e^{-m_{2} y}+l_{18} e^{-m_{3} y} \\
\phi_{1}= & 0
\end{aligned}
$$

We obtain velocity temperature and concentration area as substituted Eq. (21) to Eq. (26) in Eq. (13).

$$
\begin{aligned}
& u=l_{3} e^{-m_{1} y}+l_{4} e^{-m_{2} y}+\left(-l_{2}-l_{3}\right) e^{-m_{3} y}+E\left(l_{13} e^{-2 m_{1} y}+l_{12} e^{-2 m_{2} y}\right. \\
& \left.+l_{11} e^{-2 m_{3} y}+l_{14} e^{-m_{4} y}+l_{15} e^{-m_{5} y}+l_{16} e^{-m_{6} y}+l_{17} e^{-m_{2} y}+l_{18} e^{-m_{3} y}\right) \\
& \theta=l_{1} e^{-m_{1} y}+\left(1-l_{1}\right) e^{-m_{2} y}+E\left(l_{6} e^{-2 m_{1} y}+l_{5} e^{-2 m_{2} y}+l_{4} e^{-2 m_{3} y}\right. \\
& \left.+l_{7} e^{-m_{4} y}+l_{8} e^{-m_{5} y}+l_{9} e^{-m_{6} y}+l_{10} e^{-m_{2} y}\right) \\
& \phi=e^{-m_{1} y}
\end{aligned}
$$




$$
\begin{aligned}
C_{f}=\left(\frac{\partial u}{\partial y}\right)_{y=0} & =\left[m_{3}\left(l_{2}+l_{3}\right)-m_{2} l_{2}-m_{1} l_{3}\right] \\
& +E\left[-m_{3} l_{18}-2 m_{3} l_{11}-2 m_{2} l_{12}-2 m_{1} l_{13}-m_{4} l_{14}-m_{5} l_{15}-m_{6} l_{16}-m_{2} l_{17}\right]
\end{aligned}
$$

\subsection{Nusselt Number}

The rate of heat transfer calculated by

$$
N u=\left[m_{2}\left(1-l_{1}\right)+m_{1} l_{1}\right]+E\left[2 m_{3} l_{4}+2 m_{2} l_{5}+2 m_{1} l_{6}+m_{4} l_{7}+m_{5} l_{8}+m_{6} l_{9}+m_{2} l_{10}\right]
$$

\subsection{Sherwood Number}

The amount of Sherwood indicates the amount of mass transfer on the wall.

$$
S h=-\left(\frac{\partial \phi}{\partial y}\right)_{y=0}=m_{1}
$$

\section{The Analytcal Approch Arrived at and the Subsequent Studies}

We have plotted velocity, temperature, and concentration profiles to obtain the physical insight into the issue and address both the equations. We employ $S c=022, \operatorname{Pr}=0.71, G m=5, F=1, Q=1, E=0.2$, $R=1, D u=1, \alpha=\pi / 3, \xi=\pi / 6, G r=5, K=1, K 0=1, M=2$.

Figure 2 to Figure 7 display liquid velocity differences the influence of various specifications. Figure 2 depicts the speed outcomes for diverse Grashof number $(G r)$ values. This figure indicates that the pace rises with a rise in Gr. Figure 3 illustrates the Grashof number $(\mathrm{Gm})$ influence, as $\mathrm{Gm}$ rises, and the rate rises. The differences in velocity profiles for various permeability parameter $(K)$ values are shown in Figure 4. From where it is found that the speed increases with $\mathrm{K}$. Velocity profiles with the difference in " $\mathrm{M}$ " are shown in Figure 5 . It is noted that velocity is decreased by the magnet parameter (M). The velocity profile differences for various values of the aligned magnetic angle $(\alpha)$ are seen in Figure 6, which illustrates that the velocity decreases as $\alpha$ increase. Figure 7 indicates the inclined angle parameter $(\xi)$, velocity as declines with enhancing values of $\xi$.

Figure 8 to Figure 13 indicate fluid temperature fluctuations under the influence of numerous parameters. It is evident from models 8-10. That with the raised prandtl amount (Pr), Radiation (F) and Heat source Specification (Q) the temperature is downfallen. The influence of the Eckert number (E) on the temperature profile is seen in Figure 11. From this figure, an increment of temperature if enhancing values of "E". A related influence is identified from the Figure 12 and Figure 13, which also raises the fluid temperature in the presence of Radiation absorption and Dufour parameter.

To evaluate the effect of Figure 14, the spices graphs of the Schmidt parameter (Sc). The result indicates that the concentration field reduces. In Figure 15, the concentration profiles for various values chemically derived changes parameters $\left(K_{0}\right)$ suggest that the concentration decreases with the increasing amount of the chemical reaction parameter 


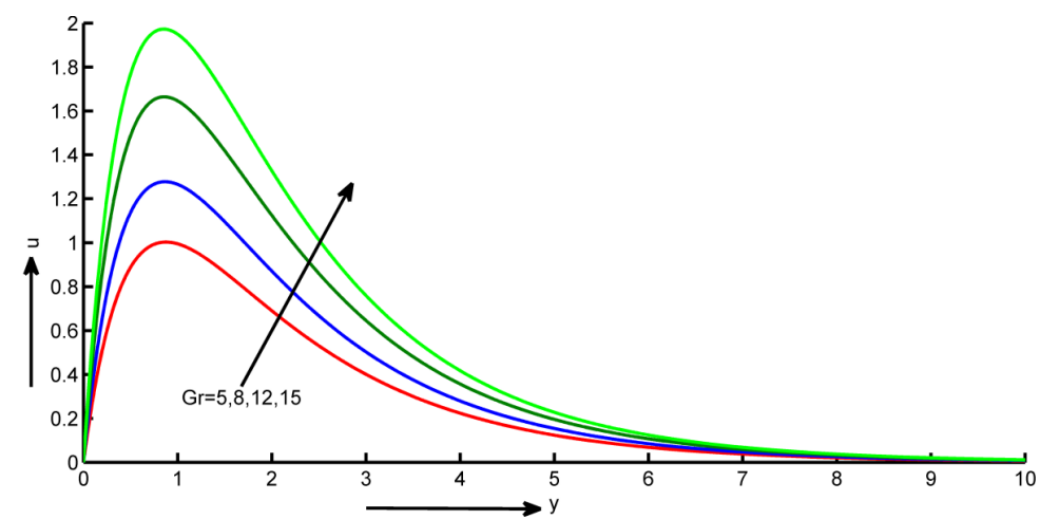

Fig. 2. Distribution of $\mathrm{u}$ on $\mathrm{Gr}$

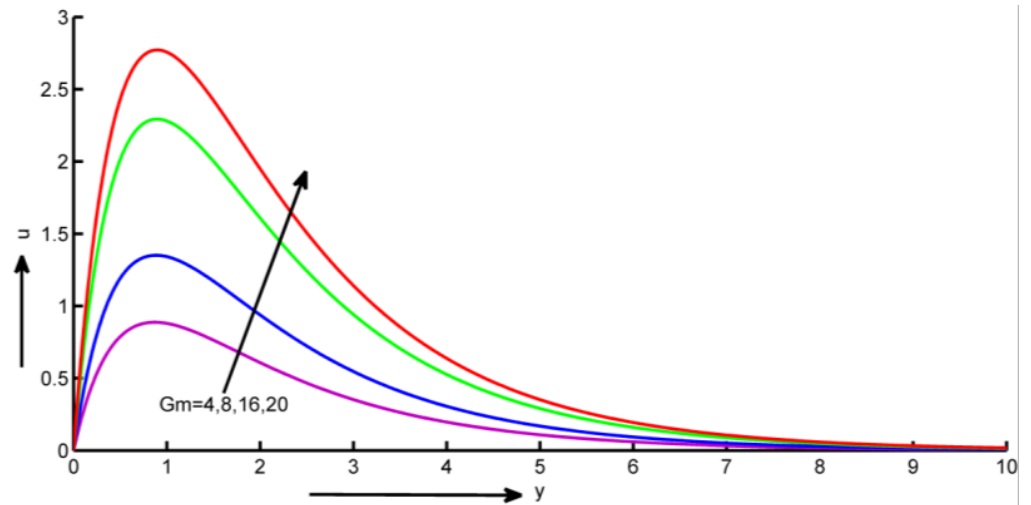

Fig. 3. Distribution of $\mathrm{u}$ on $\mathrm{Gm}$

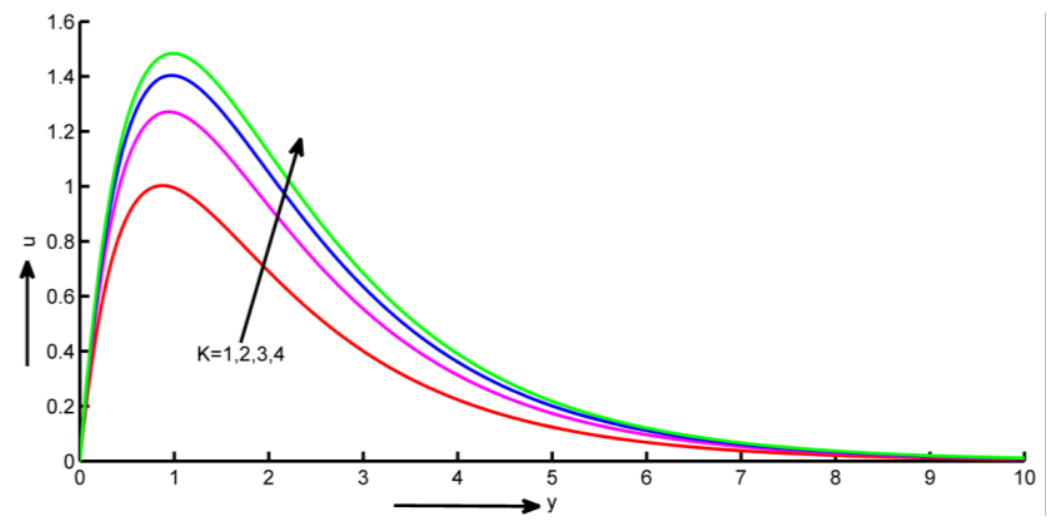

Fig. 4. Distribution of $\mathrm{u}$ on $\mathrm{K}$

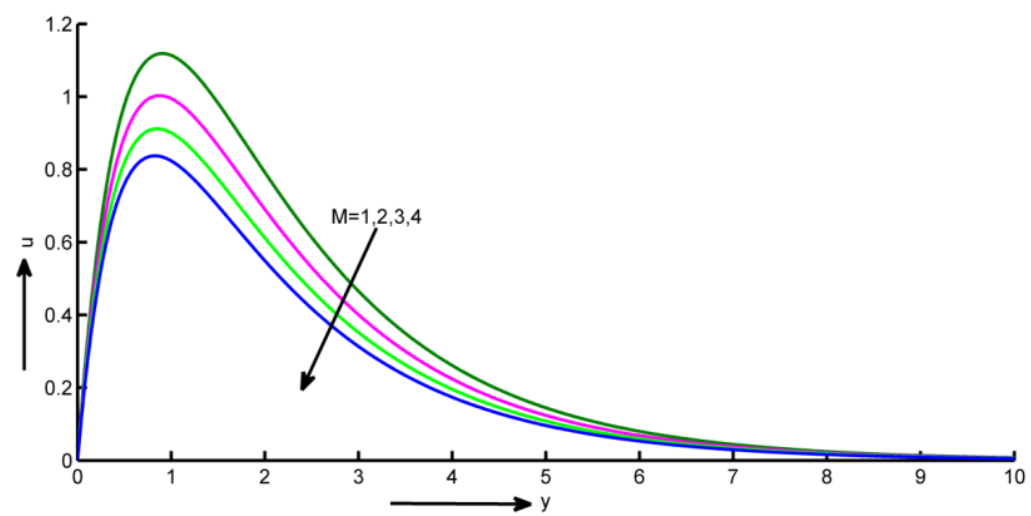

Fig. 5. Distribution of $u$ on $M$ 


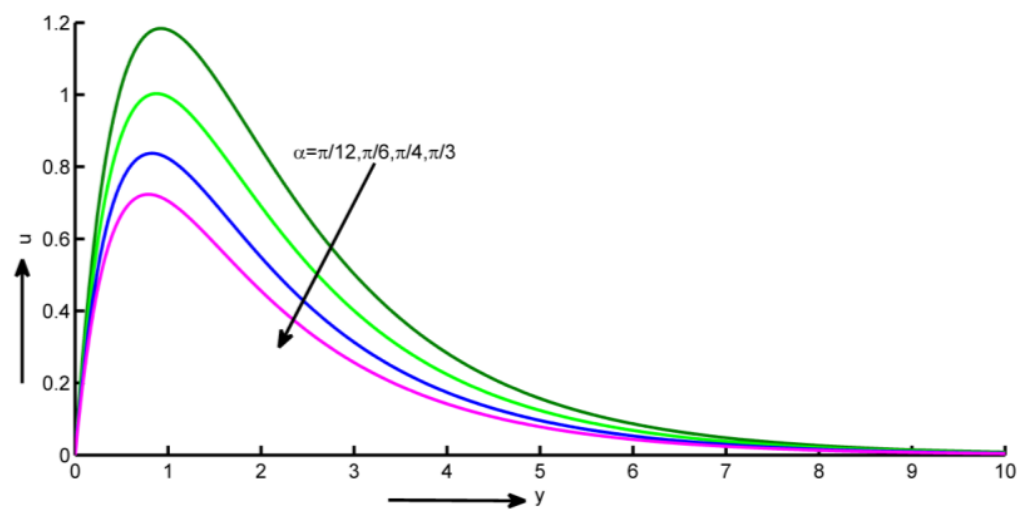

Fig. 6. Distribution of $u$ on $\alpha$

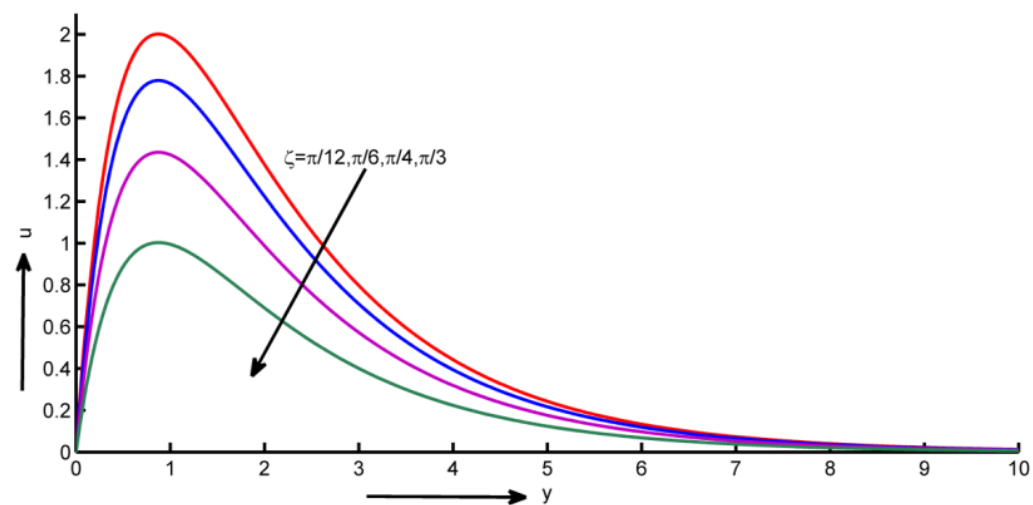

Fig. 7. Distribution of $u$ on $\xi$

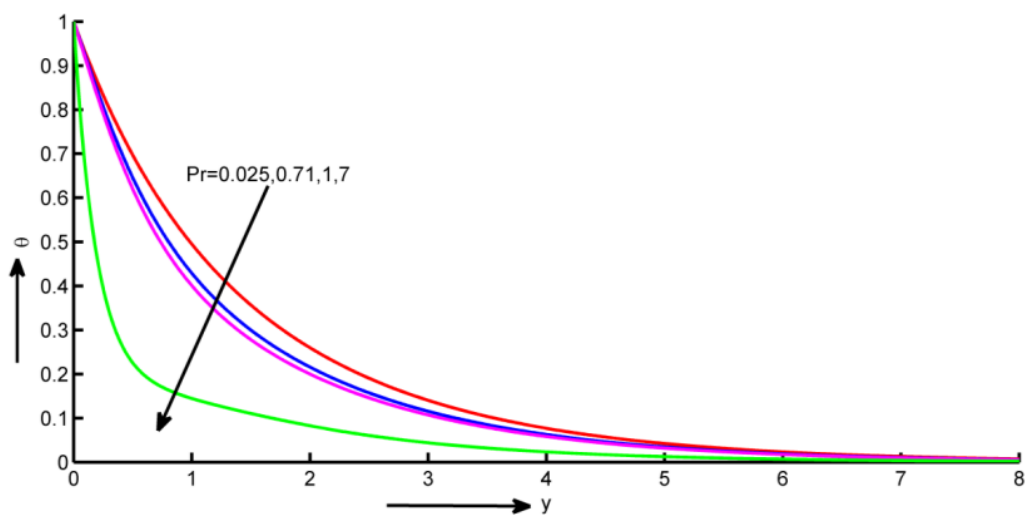

Fig. 8. Distribution of $\theta$ on $\mathrm{Pr}$

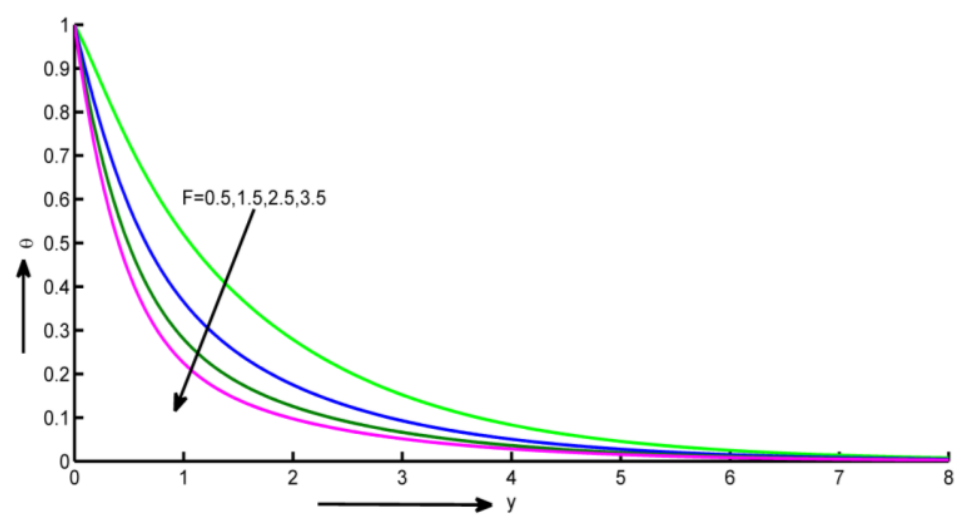

Fig. 9. Distribution of $\theta$ on $F$ 


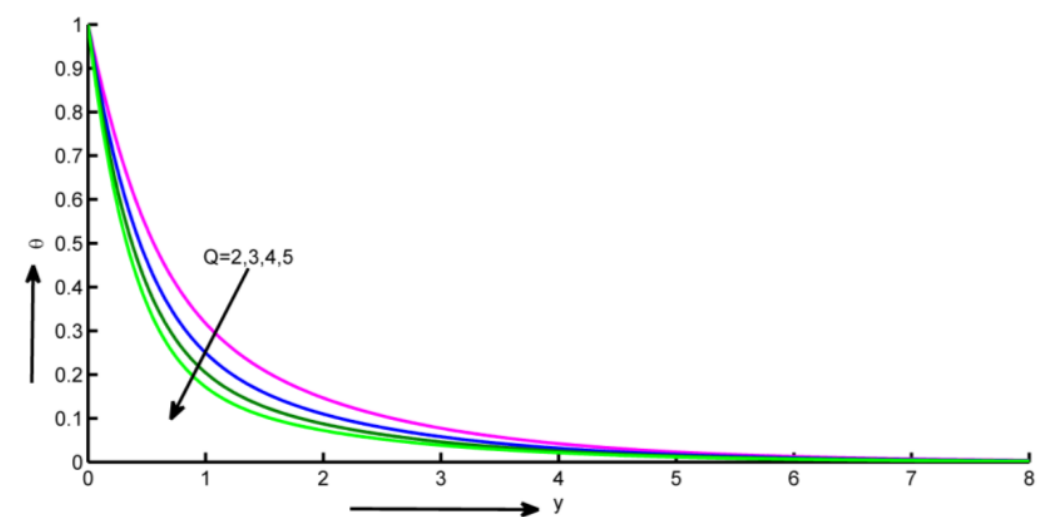

Fig. 10. Distribution of $\theta$ on $Q$

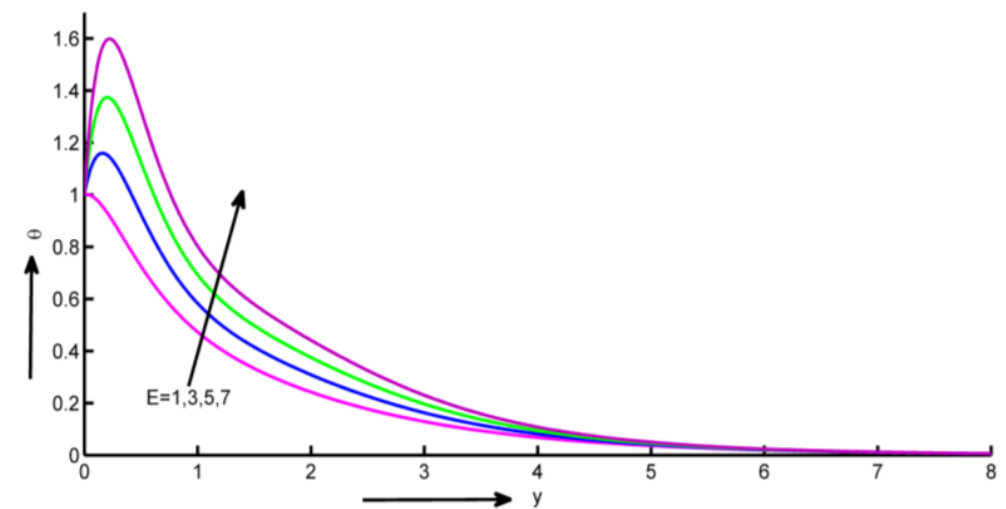

Fig. 11. Distribution of $\theta$ on $E$

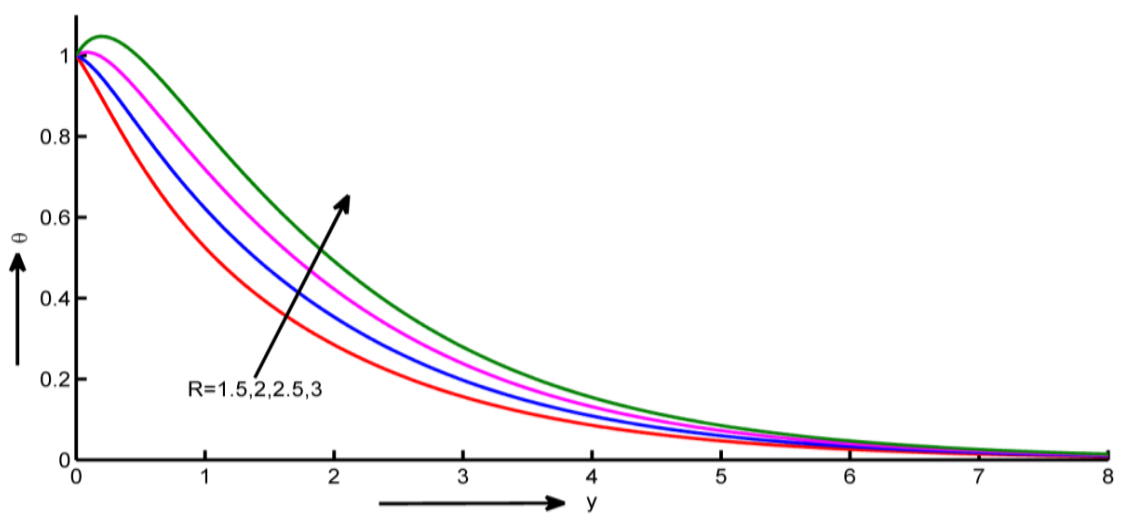

Fig. 12. Distribution of $\theta$ on $R$

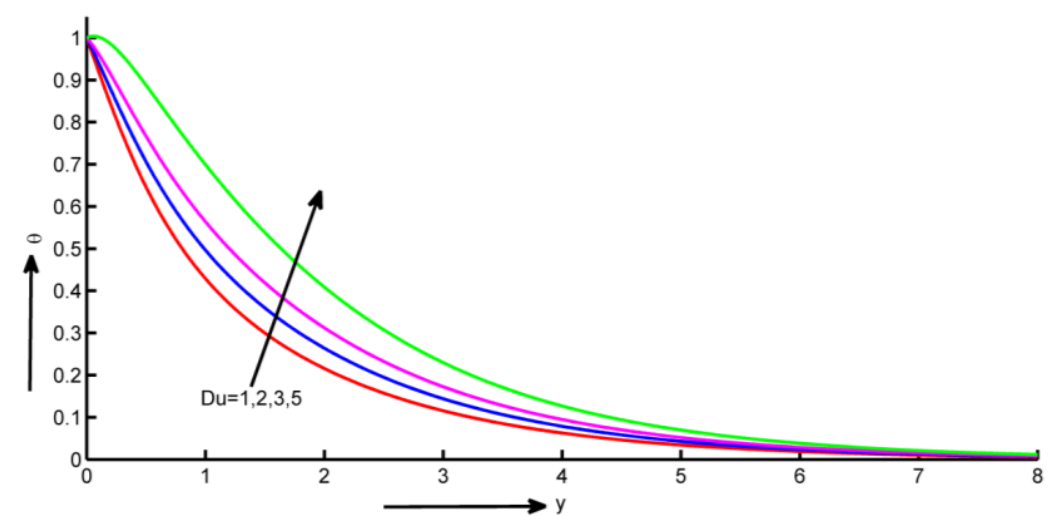

Fig. 13. Distribution of $\theta$ on $\mathrm{Du}$ 


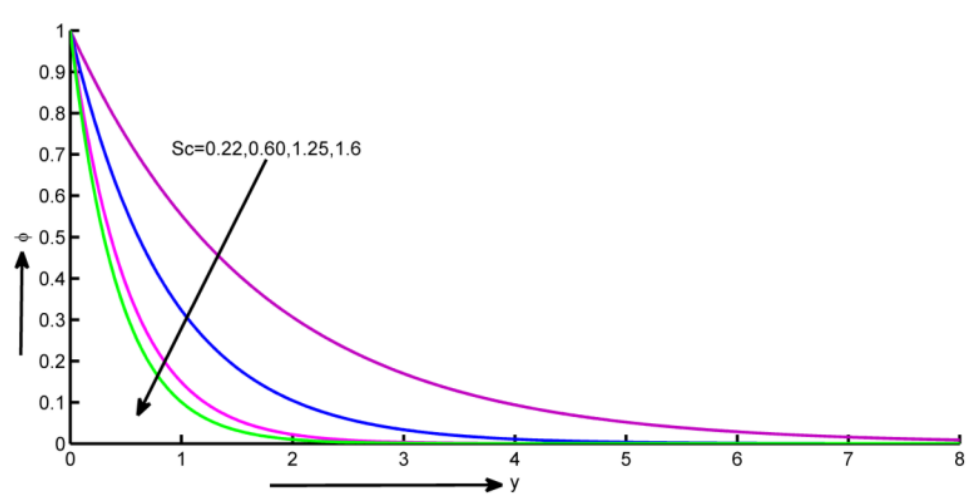

Fig. 14. Distribution of $\phi$ on Sc

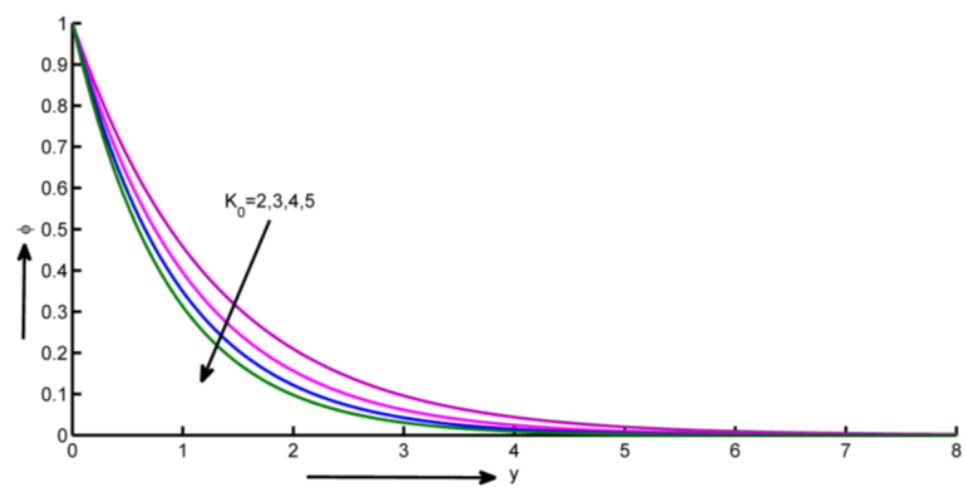

Fig. 15. Distribution of $\phi$ on $\mathrm{K}_{0}$

Figure 2 and Figure 3 exhibits the effect of Grashof number for heat and mass transfer on the velocity profile with other parameters are fixed. The Grashof number for heat transfer signifies the relative effect of the thermal buoyancy force to the viscous hydrodynamic force in the boundary layer. As expected, it is observed that there is a rise in the velocity due to the enhancement of thermal buoyancy force. Also, as $\mathrm{Gr}$ increases, the peak values of the velocity increase rapidly near the porous plate and then decays smoothly to the free stream velocity.

The Grashof number for mass transfer defines the ratio of the species buoyancy force to the viscous hydrodynamic force. As expected, the fluid velocity increases and the peak value is more distinctive due to increase in the species buoyancy force. The velocity distribution attains a distinctive maximum value in the vicinity of the plate and then decreases properly to approach the free stream value. It is noticed that the velocity increases with increasing values of the Grashof number for mass transfer.

Figure 4 is sketched in order to explore the variations of permeability parameter $\mathrm{K}$. It is found that the velocity increases with increasing values of $K$. This is due to the fact that increasing values of $\mathrm{K}$ reduces the drag force which assists the fluid considerably to move fast.

The effect of Magnetic field parameter (Hartmann number) on the velocity is shown in Figure 5. The velocity decreases with an increase in the Hartmann number. It is because that the application of transverse magnetic field will result a resistive type force (Lorentz force) similar to drag force which tends to resist the fluid flow and thus reducing its velocity. Also, the boundary layer thickness decreases with an increase in the Hartmann number.

The effect of angle of inclination to the vertical direction on the velocity is shown in Figure 6. From this figure we observe that the velocity is decreased by increasing the angle of inclination due to the fact that as the angle of inclination increases the effect of the buoyancy force due to thermal diffusion decreases by a factor of $\cos \xi$. Consequently, the driving force to the fluid decreases as a result there is decrease in the velocity profile and also similar effect that the velocity profile 
differences for various values of the aligned magnetic angle $(\alpha)$ are seen in Figure 7 , which illustrates that the velocity decreases as $\alpha$ increase.

Figure 8 shows the relationship between the temperature curve and y using different values of the number Prandtl (Pr). This number indicates that the temperature profile decreases as Prandtl number increases. This is because the fluid is highly conductive to the small values of the Prandtl number. Physically, as the Prandtl number increases, thermal diffusivity decreases and this phenomenon leads to a decrease in energy transfer capacity, which reduces the thermal interface.

The effect of thermal radiation parameter on temperature profiles against $y$ is displayed in Figure 9. It is observed from Figure 9 that the temperature profiles decrease as the thermal radiation parameter increases. This result qualitatively agrees with expectation, since the effect of radiation is to decrease the rate of energy transport to the fluid, thereby decreasing the temperature of the fluid.

The effect of heat absorption parameter on the temperature profile is shown in Figure 10. It is observed that the temperature profiles decrease as the heat absorption parameter increases. Physically speaking, the presence of heat absorption (thermal sink) effects has the tendency to reduce the fluid temperature.

The influence of the Eckert number $(E)$ on the temperature profile is seen in Figure 11. From this figure, an increment of temperature if enhancing values of " $\mathrm{E}$ ". A related influence is identified from the Figure 12 and Figure 13, which also raises the fluid temperature in the presence of radiation absorption and Dufour parameter.

Influence of Schmidt number on concentration is shown in Figure 14, from this figure it is noticed that concentration decreases with an increase in Schmidt number. Because, Schmidt number is a dimensionless number defined as the ratio of momentum diffusivity and mass diffusivity, and is used to characterize fluid flows in which there are simultaneous momentum and mass diffusion convection processes. Therefore, concentration boundary layer decreases with an increase in Schmidt number.

Figure 15 depicts the influence of chemical reaction effect $\mathrm{KO}$ on the concentration profile. It can be seen that the concentration decreases with an increase in the values of chemical reaction parameter and hence the solutal boundary layer thickness becomes thinner.

Table 1

Variations in Skin Friction coefficient

\begin{tabular}{|c|c|c|c|c|c|c|}
\hline $\mathrm{Gr}$ & $\mathrm{Gm}$ & K & $M$ & $\xi$ & $\alpha$ & $\tau$ \\
\hline 5 & & & & & & 3.2876 \\
\hline 8 & & & & & & 4.2357 \\
\hline \multirow[t]{16}{*}{10} & & & & & & 4.8885 \\
\hline & 6 & & & & & 3.6501 \\
\hline & 8 & & & & & 4.3779 \\
\hline & 12 & & & & & 5.8452 \\
\hline & & 2 & & & & 3.8399 \\
\hline & & 4 & & & & 4.2587 \\
\hline & & 6 & & & & 4.4348 \\
\hline & & & 2 & & & 3.2876 \\
\hline & & & 2.5 & & & 3.1848 \\
\hline & & & 3 & & & 3.0915 \\
\hline & & & & $\pi / 12$ & & 6.5510 \\
\hline & & & & $\pi / 6$ & & 5.8255 \\
\hline & & & & $\pi / 4$ & & 4.7029 \\
\hline & & & & & $\pi / 6$ & 3.2876 \\
\hline & & & & & $\pi / 4$ & 2.9282 \\
\hline & & & & & $\pi / 3$ & 2.6696 \\
\hline
\end{tabular}


Table 2

\begin{tabular}{|c|c|c|c|c|c|c|}
\hline $\mathrm{Pr}$ & $\mathrm{F}$ & $\mathrm{Q}$ & $E$ & $\mathrm{R}$ & $\mathrm{Du}$ & $\mathrm{Nu}$ \\
\hline 0.71 & & & & & & 0.7888 \\
\hline 1 & & & & & & 0.8416 \\
\hline \multirow[t]{16}{*}{7} & & & & & & 4.3659 \\
\hline & 2 & & & & & 1.2683 \\
\hline & 4 & & & & & 1.9414 \\
\hline & 6 & & & & & 2.4438 \\
\hline & & 1 & & & & 0.7888 \\
\hline & & 3 & & & & 1.6359 \\
\hline & & 5 & & & & 2.2067 \\
\hline & & & 2 & & & -1.2604 \\
\hline & & & 3 & & & -2.3988 \\
\hline & & & 4 & & & -3.5372 \\
\hline & & & & 2.5 & & -0.2127 \\
\hline & & & & 3 & & -0.5521 \\
\hline & & & & 5 & & -1.9380 \\
\hline & & & & & 0.5 & 0.9040 \\
\hline & & & & & 2 & 0.5572 \\
\hline & & & & & 4 & 0.0900 \\
\hline
\end{tabular}

Table 3

Variant factors in Sherwood

\begin{tabular}{lll}
\hline Sc & $\mathrm{K}_{0}$ & Sh \\
\hline 0.22 & & 0.5918 \\
0.60 & & 1.1307 \\
1.6 & & 2.2967 \\
& 0.5 & 0.4594 \\
& 1.5 & 0.6949 \\
& 3 & 0.9298 \\
\hline
\end{tabular}

\section{Conclusion}

This paper has examined heat MHD and the steady movement of convective fluid through a porous plate with a diffusion-thermo and aligned magnetic field. The following assumptions are taken in the study of the flow:

- Fluid velocity rises with raised Grashof amount and changed Grashof quantities. The porous medium permeability parameter decreased as the Magnetic parameter, magnetic field parameter aligned $(\alpha)$, and angle parameter inclined.

- In the existence of $\operatorname{Pr}, F, Q, R$, the reality of Eckert number, and Dufour amounts, the fluid temperature rises.

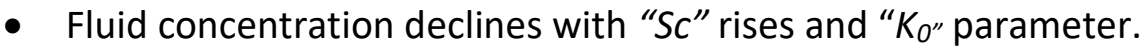

- Skin friction coefficient is accelerated due to an improvement in porous K, thermal Grashof solutal number $\mathrm{Gm}$. In contrast, the decrease is due to the $\xi$, $\alpha$ and magnetic field parameter M.

- Nusselt number rises in Prandtl numbers $\operatorname{Pr}$, heat absorption $Q$, radiation parameter $F$, and falls in Dufour numbers Du, radiation absorption parameter $\mathrm{R}$, and Eckert number $\mathrm{E}$.

- With the "SC" and " $\mathrm{K}_{0}$ " the chemical reaction parameter's increasing values, the mass transfer rate "Sh" raises. 


\section{References}

[1] Raju, K. Venkateswara, A. Parandhama, M. C. Raju, and K. Ramesh Babu. "Unsteady MHD mixed convection flow of Jeffrey fluid past a radiating inclined permeable moving plate in the presence of thermophoresis heat generation and chemical reaction." Journal of Ultra Scientist of Physical Sciences 30, no. 1 (2018): 51-65.

[2] Vedavathi, N., G. Dharmaiah, K. S. Balamurugan, and G. Charan Kumar. "Chemical reaction, radiation and dufour effects on casson magneto hydro dynamics fluid flow over a vertical plate with heat source/sink." Global Journal of Pure and Applied Mathematics 12, no. 1 (2016): 191-200.

[3] Ramaiah, P., and K. Rama Krishna Prasad. "Aligned Magnetic Field and Diffusion Thermo Effect on Unsteady MHD Free Convective Flow past an Inclined Surface." International Journal of Advanced Scientific Research and Management 4, no. 7 (2019).

[4] Rich, B. R. "An investigation of heat transfer from an inclined flat plate in free convection." Transactions of the ASME 75 (1953): 489-499.

[5] Chen, T. S., Hwa-Chong Tien, and Bassem F. Armaly. "Natural convection on horizontal, inclined, and vertical plates with variable surface temperature or heat flux." International Journal of Heat and Mass Transfer 29, no. 10 (1986): 1465-1478. https://doi.org/10.1016/0017-9310(86)90061-X

[6] Yu, W-S., and H-T. Lin. "Free convection heat transfer from an isothermal plate with arbitrary inclination." Wärmeund Stoffübertragung 23, no. 4 (1988): 203-211. https://doi.org/10.1007/BF01807322

[7] Muthucumaraswamy, R. "MHD and radiative flow past an vertical oscillating plate with chemical reaction of first order." Emirates Journal for Engineering Research 18, no. 1 (2012): 1-10.

[8] Ramaprasad, J. L., K. S. Balamurugan, and G. Dharmaiah. "Unsteady mhd convective heat and mass transfer flow past an inclined moving surface with heat absorption." JP Journal of Heat and Mass Transfer 13, no. 1 (2016): 3351. https://doi.org/10.17654/HM013010033

[9] Kumaresan, E., and AG Vijaya Kumar. "An exact solution on unsteady MHD viscoelastic fluid flow past an infinite vertical plate in the presence of thermal radiation." Frontiers in Heat and Mass Transfer 8 (2017): 1-7. https://doi.org/10.5098/hmt.8.9

[10] Balamurugan, K. S., and Ch V. Ramana Murthy. "Radiation absorption and viscous-dissipation effects on magnetohydrodynamic free-convective flow past a semi-infinite, moving, vertical, porous plate." International Journal of Fluid Mechanics Research 45, no. 5 (2018): $439-458$. https://doi.org/10.1615/InterJFluidMechRes.2018024790

[11] Nandkeolyar, Raj, Bhupesh Kumar Mahatha, Goutam Kumar Mahato, and Precious Sibanda. "Effect of chemical reaction and heat absorption on MHD nanoliquid flow past a stretching sheet in the presence of a transverse magnetic field." Magnetochemistry 4, no. 1 (2018): 18. https://doi.org/10.3390/magnetochemistry4010018

[12] Mohapatra, R., H. Pattanayak, and S. R. Mishra. "Effect of Chemical Reaction on MHD Micropolar Fluid Flow on a Vertical Surface through Porous Media with Heat Source." International Journal of Innovative Research in Science, Engineering and Technology 4, no. 9 (2015).

[13] Srinivas Reddy, D. "Impact of chemical reaction on MHD free convection heat and mass transfer from vertical surfaces in porous media considering thermal diffusion and diffusion thermo effects." Pelagia Research Library Advances in Applied Science Research 7, no. 4 (2016): 235-242.

[14] Sheri, Siva Reddy, and M. D. Shamshuddin. "Diffussion-thermo and chemical reaction effects on an unsteady MHD free convection flow in a micropolar fluid." Theoretical and Applied Mechanics 43, no. 1 (2016): 117-131. https://doi.org/10.2298/TAM160223007S

[15] Malik, M. Y., and Khalil-ur-Rehman. "Effects of second order chemical reaction on MHD free convection dissipative fluid flow past an inclined porous surface by way of heat generation: A Lie group analysis." Information Sciences Letters 5, no. 2 (2016): 35-45. https://doi.org/10.18576/isl/050201

[16] Kumar, G. Charan, Konda Jayarami Reddy, Rama Krishna Konijeti, and M. Narendradh Reddy. "Non-uniform heat source/sink and joule heating effects on chemically radiative MHD mixed convective flow of micropolar fluid over a stretching sheet in porous medium." In Defect and Diffusion Forum, vol. 388, pp. 281-302. Trans Tech Publications Ltd, 2018. https://doi.org/10.4028/www.scientific.net/DDF.388.281

[17] Rao, Abburi Sreenivasa, Peddi Phani Bushan Rao, and Charan Kumar Ganteda. "Magnetohydrodynamic Williamson fluid motion over an exponentially stretching sheet with chemically radiative heat source effects under suction/injection." Journal of Mathematical and Computational Science 10, no. 6 (2020): 2634-2657.

[18] Krishnarao, B. Venkata, Jayaramireddy Konda, and Charankumar G. "MHD and Thermal Radiation Effects of a Nanofluid over a Stretching Sheet using HAM." International Journal of Recent Technology and Engineering 8, no. 4 (2019): 3489-3496. https://doi.org/10.35940/ijrte.C6726.118419

[19] Rao, Abburi Sreenivasa, Peddi Phani Bushan Rao, and Charan Kumar Ganteda. "Influence of heat source effect on MHD flow of casson fluid over a nonlinearly stretching sheet with chemical reaction and slip conditions." 
International Journal of Mechanical and Production Engineering Research and Development 10, no. 2 (2020): 15111528.

[20] Cogley, A. C., S. E. Gilles, and W. G. Vincenti. "Differential approximation for radiative transfer in a nongrey gas near equilibrium." AIAA Journal 6, no. 3 (1968): 551-553. https://doi.org/10.2514/3.4538

[21] Salbi, Noorsabrina M., Norhayati Muhammad, and Norazlin Abdullah. "The Effect of Maltodextrin and Acacia Gum on Encapsulation of Fig Powder Physicochemical Properties." Journal of Advanced Research in Applied Sciences and Engineering Technology 22, no. 1 (2021): 8-15. https://doi.org/10.37934/araset.22.1.815

[22] Khan, Ansab Azam, Khairy Zaimi, Suliadi Firdaus Sufahani, and Mohammad Ferdows. "MHD Flow and Heat Transfer of Double Stratified Micropolar Fluid over a Vertical Permeable Shrinking/Stretching Sheet with Chemical Reaction and Heat Source." Journal of Advanced Research in Applied Sciences and Engineering Technology 21, no. 1 (2020): 1-14. https://doi.org/10.37934/araset.21.1.114

[23] Phu, Nguyen Minh, Pham Ba Thao, and Duong Cong Truyen. "Heat and Fluid Flow Characteristics of Nanofluid in A Channel Baffled Opposite to The Heated Wall." CFD Letters 13, no. 1 (2021): 33-44. https://doi.org/10.37934/cfdl.13.1.3344

[24] Mahat, Rahimah, Sharidan Shafie, and Fatihhi Januddi. "Numerical Analysis of Mixed Convection Flow Past a Symmetric Cylinder with Viscous Dissipation in Viscoelastic Nanofluid." CFD Letters 13, no. 2 (2021): 12-28. https://doi.org/10.37934/cfdl.13.2.1228

[25] Azman, Azraf, Mohd Zamri Yusoff, Azfarizal Mukhtar, Prem Gunnasegaran, Nasri A. Hamid, and Ng Khai Ching. "Numerical Study of Heat Transfer Enhancement for Mono and Hybrid Nanofluids Flow in a Straight Pipe." CFD Letters 13, no. 2 (2021): 49-61. https://doi.org/10.37934/cfdl.13.2.4961 